\title{
Determination of the Perceived Contrast Compensation Ratio for a Wide Range of Surround Luminance
}

\author{
Ye Seul Baek, Hong-suk Kim, and Seung-ok Park* \\ Department of Physics, Daejin University, Pocheon 487-711, Korea
}

(Received August 9, 2013 : revised November 18, 2013 : accepted December 2, 2013)

\begin{abstract}
It is established that the perceived image contrast is affected by surround luminance. In order to get the same perceived image contrast, the optimum surround compensation ratios for those surround conditions is needed. Much research has been performed for dark, dim, and average surrounds. In this study, a wide range of surround luminance from dark up to $2087 \mathrm{~cd} / \mathrm{m}^{2}$ was considered. Using magnitude estimation method, the change in perceived brightness of six test stimuli was measured under seven surround conditions; dark, dim, 2 levels of average, bright, and 2 levels of over-bright surrounds. To drive the perceived image contrast from the perceived brightness, two different definitions of contrast were tested. Their calculated results were compared with the visual data of our previous work. And to conclude, the perceived contrast compensation ratios were 1:1.11:1.2 for average, dim and dark surrounds. These were close to CIECAM02 model (1:1.17:1.31). Besides, for average, bright, over-bright1 and over-bright2 surrounds the ratios 1:1.17:1.42:1.69 were determined. For intermediate or more extreme surround conditions, the compensation ratio was obtained from the linear interpolation or extrapolation.
\end{abstract}

Keywords: Perceived contrast, Perceived brightness, Wide range of surround luminance, Contrast compensation ratio

OCIS codes : (330.0330) Vision, color, and visual optics; (330.1690) Color; (330.4060) Vision modeling; (330.5510) Psychophysics

\section{INTRODUCTION}

The effect of surround luminance on perceived image contrast is important, especially in the electronic displays field. A printed image is usually viewed in a fixed condition such as office lighting. However, recently, an image on monitor is allowed to be viewed under various surround conditions from dark room to bright outdoors. Hence, the perceived image contrast is changed according to different surround condition such as different luminance levels. It is a huge issue in color science and image quality engineering.

Several investigators $[1,2]$ performed brightness scaling studies to explore the background or surround effect. For example, Stevens and Stevens [1] examined the effect of adaptation on brightness scaling. Stevens specified perceived brightness as a power function of surround luminance. The exponent of power function can be explained by contrast. As the adapting field increases in luminance, the power exponent increases. This means that perceived contrast increases as the surround luminance increases. Also, Bartleson [2] examined the surround effect on lightness in light, dim and dark surrounds. The experimental result showed that the power exponents are $0.50,0.41$ and 0.33 for light, dim and dark surrounds, respectively. It indicates that the image viewed in dark surround must be about 1.5 times higher than in light surround. This value of 1.5 can be used as the contrast compensation ratio for dark surround. In the case of dim surround, the contrast compensation ratio is 1.25 .

There is much literature [3-6] to verify the contrast compensation ratios. The RLAB color appearance model $[3,4]$ includes surround dependency to match the color appearance attributes across different viewing conditions. RLAB lightness was modeled based on power function. The power exponents were $0.43,0.34$, and 0.29 , for average, dim, and dark surrounds. The corresponding contrast compensation ratios were 1:1.26:1.48 and these are very close to the classical result from Bartleson \& Breneman

\footnotetext{
*Corresponding author: sopark@daejin.ac.kr

Color versions of one or more of the figures in this paper are available online.
} 
[7]. CIECAM 97s [5] and CIECAM02 [6] have been developed by the CIE. These models are also based on power function to estimate the lightness. The surround parameter for an average surround is 0.69 , for a dim surround is 0.59 and for a dark surround is 0.525 . Accordingly the surround compensate image gamma ratios are 1:1.17:1.31 for average, dim and dark surround. [8]

We aim to determine the perceived contrast compensation ratios for a wide range of surround luminance including dark, dim, average, bright, over-bright 1 and over-bright 2 surrounds. In our previous work [9], the change in perceived image contrast for a wide range of surround luminance was measured in Z-scale value. A set of paired comparison experiments was conducted to compare the perception of image contrast under a wide range of surround luminance covering from 0 up to $2087 \mathrm{~cd} / \mathrm{m}^{2}$. The results showed that the perceived image contrast changed according to surround luminance and the maximum perceived image contrast was found near a surround ratio $\left(S_{R}\right)$ of $1 . S_{R}$ is the surround luminance relative to the display peak white. As $S_{R}$ increases from 0 to 1 , black appears darker and darker and white is not very much affected, and the image contrast becomes higher. It can be fully explained by the Bartleson and Breneman effect. [7] However, when $S_{R}>1$, black becomes stabilized into a certain level but white gets dimmer and dimmer; therefore, observers eventually perceive a lower image contrast. Yet this tendency has not been proved by other researchers. However, recently much research mentioned that CIECAM02 poorly estimates the brightness under bright surround conditions [10-12].

The present work tries to drive the perceived image contrast from the perceived brightness using two definitions. Their results are compared with the visual data of our previous work [7]. In conclusion, the perceived contrast compensation ratios for seven levels of surround luminance are determined.

\section{PSYCHOPHYSICAL EXPERIMENT ON BRIGHTNESS PERCEPTION}

\subsection{Experimental Setup}

In order to investigate the surround luminance effect on perceived image contrast, a large-format flat illuminator has been built. This illuminator is made up of a cold cathode fluorescent lamp (CCFL), and its physical size is $2400 \times$ $1300 \mathrm{~mm}$. As shown in Fig. 1, the illuminator is attached to the wall to form a surround and an LCD display is placed with its back toward the illuminator to minimize the viewing flare. The experimental viewing room (including the ceiling and the wall) is also painted matte black.

A Minolta CA2000 2D color analyzer is used to measure with measuring angle of $10^{\circ}$. The specifications of seven surround conditions are listed in Table 1. $Y$ is the luminance in $\mathrm{cd} / \mathrm{m}^{2}, \mathrm{~S}_{\mathrm{R}}$ is the luminance ratio of surround relative to the display peak white $\left(180 \mathrm{~cd} / \mathrm{m}^{2}\right)$ defined as follows [6],

$$
S_{R}=\frac{\text { luminance of surround }\left(Y_{S}\right)}{\text { luminance of monitor }\left(Y_{m}\right)}
$$

CCT is the correlated color temperature of illuminated light, and VF the amount of viewing flare. These surround conditions cover the wide range of surround luminance from dark to over- bright:

$\mathrm{S}_{\mathrm{R}} \approx 0$ defines dark surround $\mathrm{D}, 0<\mathrm{S}_{\mathrm{R}} \leq 0.35$ define $\operatorname{dim}$ surround $\mathrm{Dm}, 0.35<\mathrm{S}_{\mathrm{R}} \leq 1$ define average surrounds $\mathrm{A} 1$ and $\mathrm{A} 2,1<\mathrm{S}_{\mathrm{R}} \leq 5$ define bright surround $\mathrm{B}$ and $5<\mathrm{S}_{\mathrm{R}}$ define over-bright surrounds $\mathrm{OB} 1$ and $\mathrm{OB} 2$. The average CCT is about $7500 \mathrm{~K}$. The maximum VF is lower than $1.2 \%$. The effect of VF or any significant specular reflections from the LCD screen should be negligible.

Six neutral test stimuli from black to white are produced on the LCD display. A Minolta CS1000 spectroradiometer

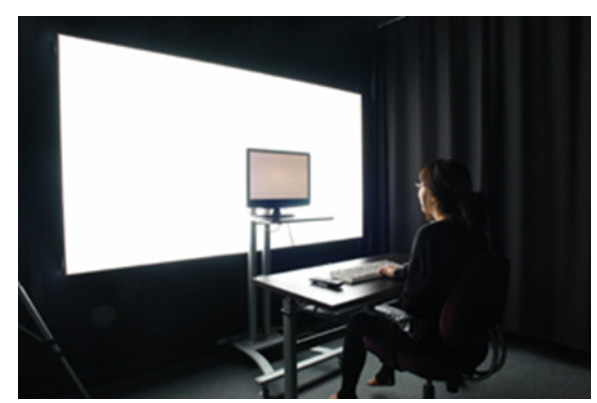

FIG. 1. Experimental environment.

TABLE 1. Measurement of surround luminance in terms of luminance, $\mathrm{CCT}$, surround ratio and viewing flare

\begin{tabular}{c|c|c|c|c}
\hline \hline $\begin{array}{c}\text { Surround } \\
\text { conditions }\end{array}$ & $Y\left(\mathrm{~cd} / \mathrm{m}^{2}\right)$ & $\mathrm{S}_{\mathrm{R}}$ & $\mathrm{CCT}(\mathrm{K})$ & $\mathrm{VF}(\%)$ \\
\hline dark (D) & 0 & 0.00 & 0 & 0 \\
\hline dim (Dm) & 62 & 0.34 & 7642 & 0.04 \\
\hline average 1 (A1) & 117 & 0.64 & 7614 & 0.07 \\
\hline average 2 (A2) & 200 & 1.10 & 7450 & 0.12 \\
\hline $\begin{array}{c}\text { bright (B) } \\
\text { over-bright 1 } \\
\text { (OB1) }\end{array}$ & 468 & 2.57 & 7383 & 0.26 \\
\hline $\begin{array}{c}\text { over-bright 2 } \\
\text { (OB2) }\end{array}$ & 2087 & 11.47 & 6984 & 1.16 \\
\hline
\end{tabular}

TABLE 2. The luminance and lightness for each test stimulus

\begin{tabular}{c|c|c}
\hline \hline Test stimulus & $Y\left(\mathrm{~cd} / \mathrm{m}^{2}\right)$ & $L^{*}$ \\
\hline $\mathrm{t} 1$ & 0.2 & 1.1 \\
\hline $\mathrm{t} 2$ & 5.2 & 19.6 \\
\hline $\mathrm{t} 3$ & 22.3 & 41.8 \\
\hline $\mathrm{t} 4$ & 53.5 & 61.4 \\
\hline $\mathrm{t} 5$ & 97.5 & 78.5 \\
\hline $\mathrm{t} 6$ & 180 & 100.0 \\
\hline
\end{tabular}


is used for measurement. The luminance of display peak white is $180 \mathrm{~cd} / \mathrm{m}^{2}$ and the CCT is $6746 \mathrm{~K}$. Because the CCT of LCD display is different from the average CCT of surrounds, the R, G, and B digital values to reproduce each test stimulus are controlled to be about $7500 \mathrm{~K}$. Table 2 summarizes the luminance $(Y)$ and CIELAB lightness $\left(L^{*}\right)$ of six test stimuli.

\subsection{Psychophysical Experiment}

Ten observers with normal color vision participate in this experiment. There are seven males and three females, whose ages ranged from 20 to 28 . Before carrying out the experiment, they are trained to recognize brightness attributes using neutral color patches of Munsell color order system. The viewing distance is set to be 3 meters from the LCD display, as shown in Fig. 1 . The viewing angle is about $9^{\circ}$ horizontally and $6^{\circ}$ vertically.

The magnitude estimation method is considered to estimate the brightness. As a reference, test stimulus t6 is shown to the observer under $\mathrm{A} 2$ surround. The observer has to memorize the brightness of the test stimulus for 1 minute, and it is designated to have brightness of 100 . At the same time, the observer's eyes are adapted to the monitor. After the observer is fully memorized and adapted to the test stimulus, surround luminance condition is changed at random order. The observers are asked to assign the degree of brightness of the test stimulus under each surround condition compared to the memory. After the experiment for a test stimulus is over, these processes are repeated for the other test stimuli. The all observations are carried out in random orders. All the experiments are repeated twice and its mean value is used to represent the subjective score. Totally 840 estimation observations ( 6 test stimuli $\times 7$ surrounds $\times$ 10 observers $\times 2$ repeat) are collected in this experiment.

\subsection{Statistical Analysis Methods}

\subsubsection{Coefficient of Variation}

To estimate the observer accuracy, the coefficient of variation $(\mathrm{CV})$ has been widely used in color appearance researches. [13] The CV is a statistical measure of the agreement between two data sets $\left(x_{i}\right.$ and $\left.y_{i}\right)$.

$$
\mathrm{CV}=100 \times \frac{\sum_{i}\left(x_{i}-y_{i}\right)^{2} / n}{\bar{y}}
$$

Where $n$ is the number of samples and $\bar{y}$ is the mean value of the $y$ set. The value of $\mathrm{CV}$ is expressed in percentages. Zero of $\mathrm{CV}$ means perfect agreement between two data sets. The larger $\mathrm{CV}$ value shows poorer agreement.

\subsubsection{Pearson Correlation}

Pearson correlation is used to measure dependence between two data sets. It can be obtained by dividing the covariance of between a pair of variables (e.g. $x$ and $y$ ) by the product of standard deviations. The Pearson correlation is written by [14]

$$
\mathrm{r}=\frac{\sum_{i-1}^{n}\left(x_{i}-\bar{x}\right)\left(y_{i}-\bar{y}\right)}{(n-1) S_{x} S_{y}}
$$

where $(n-1)$ is degree of freedom, and $\bar{x}$ and $\bar{y}$ are mean values for the $x$ and $y$ variables, respectively, and $S_{x}$ and $S_{y}$ are the covariance of $x$ and $y$, respectively. When the variables are independent, Pearson correlation is 0 . The limits on the correlation are -1 to +1 . If they are perfectly linearly related, then their Pearson correlation is +1 .

\section{RESULT AND DISCUSSION}

\subsection{Observer Performance}

The observer performance was examined using $\mathrm{CV}$ values. Table 3 shows the CV values of seven surround conditions for each observer. The last row is the average $\mathrm{CV}$ values for each observer. Among ten observers, ob8 observer shows larger $\mathrm{CV}$ values than others for all surround conditions, so it was decided to remove ob8 observer's data. The CV values of each observer showed good performance under 10. The average $\mathrm{CV}$ value was 6.2 .

\subsection{Effect of Surround Luminance on Perceived Brightness}

Figure 2 shows the perceived brightness of six stimuli for seven surround conditions. The $\mathrm{x}$-axis is luminance of

TABLE 3. Each individual's performance using CV values

\begin{tabular}{c|c|c|c|c|c|c|c|c|c|c}
\hline \hline & ob1 & ob2 & ob3 & ob4 & ob5 & ob6 & ob7 & ob8 & ob9 & ob10 \\
\hline $\mathrm{D}$ & 4 & 5 & 2 & 4 & 6 & 12 & 4 & 13 & 10 & 9 \\
\hline $\mathrm{Dm}$ & 5 & 5 & 4 & 5 & 4 & 6 & 5 & 14 & 7 & 5 \\
\hline $\mathrm{A} 1$ & 5 & 4 & 4 & 4 & 4 & 5 & 4 & 14 & 8 & 5 \\
\hline $\mathrm{A} 2$ & 5 & 4 & 4 & 3 & 4 & 5 & 4 & 14 & 7 & 5 \\
\hline $\mathrm{B}$ & 9 & 5 & 4 & 6 & 6 & 6 & 6 & 12 & 10 & 6 \\
\hline OB1 & 5 & 7 & 7 & 4 & 9 & 7 & 5 & 14 & 13 & 8 \\
\hline OB2 & 12 & 10 & 4 & 7 & 11 & 6 & 7 & 16 & 12 & 6 \\
\hline Avg. & 7 & 6 & 4 & 5 & 6 & 7 & 5 & 14 & 10 & 6 \\
\hline
\end{tabular}

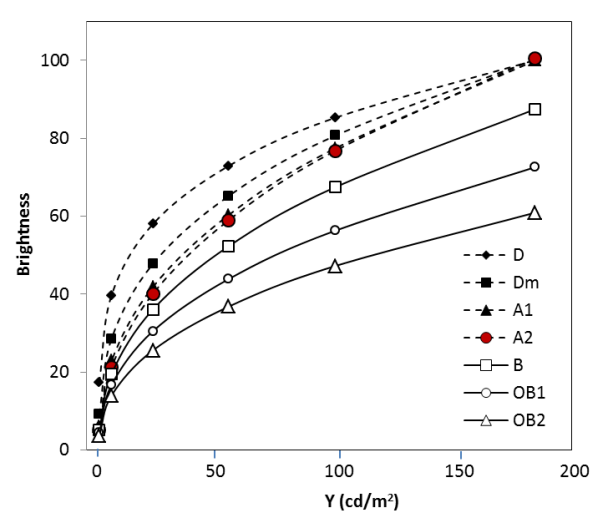

FIG. 2. The perceived brightness of six stimuli for seven surround conditions. 
stimulus and the y-axis is the perceived brightness. The brightness of white stimulus is almost unchanged at nearly 100 when the surround luminance increased from dark surround D to average surround A2 and decreased rapidly from 100 to 50 under over-bright surrounds. Figure 3, in magnified scale, shows that the brightness of black stimulus decreases when the surround luminance increased from dark surround $\mathrm{D}$ to average surround $\mathrm{A} 2$ and almost unchanged under over-bright surrounds. Figure 4 shows the perceived brightness under each surround plotted against the perceived brightness under average surround A2. In each graph, the

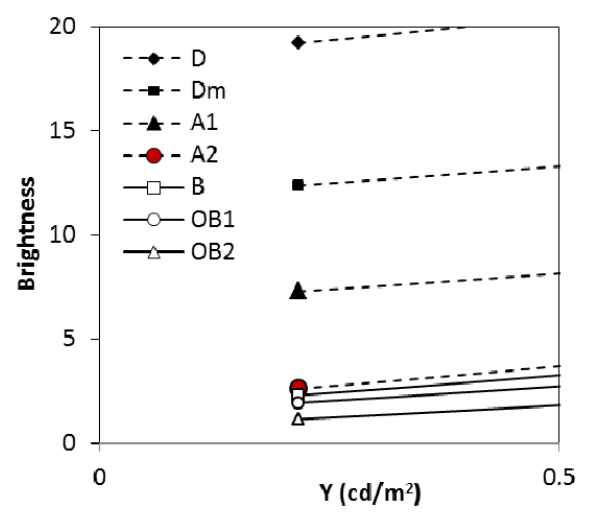

FIG. 3. The perceived brightness of black stimuli for seven surround conditions (magnified version of FIG. 2). number of data points is 54 ( 6 stimuli $\times 9$ observers). The straight line indicates a $45^{\circ}$ line. For dark surround D, data points except white are located above the $45^{\circ}$ line. This means that when the surround luminance is changed from dark surround D toward average surround A2, the black appears darker and white is not so much affected. For over-bright surrounds $\mathrm{OB} 1$ and $\mathrm{OB} 2$, data points except black are far away from the $45^{\circ}$ line. This means that when the surround luminance gets brighter from average surround A2 to over-bright surround $\mathrm{OB} 2$, the white stimulus appears grayish and the black stimulus is not so much affected.

\subsection{The Perceived Contrast Compensation Ratios}

To drive the perceived contrast from the perceived brightness, two different definitions of contrast are tried. One is the power exponent of brightness function; the other is the difference in brightness between light and dark areas in a scene.

The brightness functions which describe the perceived brightness data in Fig. 4 are modeled as a power function of surround luminance [1] shown in Eq. 4.

$$
\psi=k\left(L-L_{0}\right)^{\beta}
$$

where $\psi$ is brightness, $L$ is stimulus luminance, $L_{0}$ is the absolute threshold luminance, $k$ is a constant, and $\beta$ is the
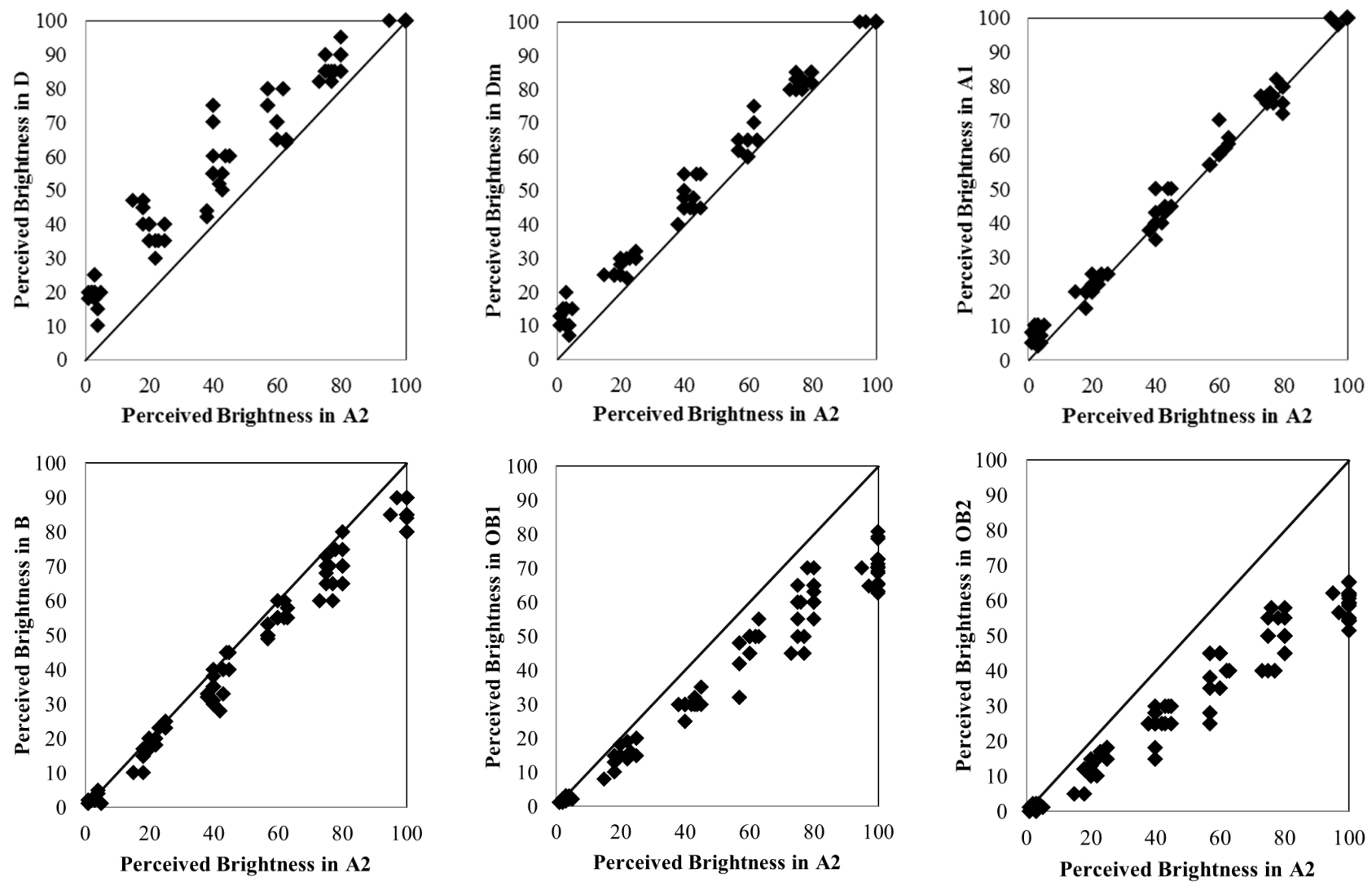

FIG. 4. The perceived brightness under each surround plotted against the perceived brightness under average surround A2. 
power exponent. Table 4 shows the parameters of brightness functions with $\mathrm{CV}$ values and Pearson correlation coefficients. It is modeled using the MS Excel Solver add-in program. $\mathrm{CV}$ values are from 1.24 to 5.66 , and Pearson correlation coefficients are near 1 . They confirm good performance of modeling.

First, the perceived image contrast is defined by the exponent $\beta$. In Fig. 5, the change in $\beta$ for seven surround conditions is compared with the visual data of our previous work [9]. As $S_{R}$ increases from 0 to 1 , the change in $\beta$ is very similar to our previous result. However when $S_{R}>1$, $\beta$ decreases very slowly and then shows slight variations, which is very different from our previous result. It is proved that the exponent $\beta$ is not proper to define the perceived image contrast when the surround luminance is higher than luminance of display white.

TABLE 4. The parameters of brightness functions

\begin{tabular}{c|c|c|c|c|c}
\hline \hline & $k$ & $L_{\mathrm{o}}$ & $\beta$ & $C V$ & $r$ \\
\hline $\mathrm{D}$ & 25.81 & 0.00 & 0.26 & 2.08 & 0.999 \\
\hline $\mathrm{A} 1$ & 15.89 & 0.00 & 0.35 & 3.22 & 0.998 \\
\hline $\mathrm{A} 2$ & 11.48 & 0.00 & 0.42 & 1.61 & 1.000 \\
\hline $\mathrm{A} 3$ & 10.69 & 0.18 & 0.43 & 1.24 & 1.000 \\
\hline $\mathrm{B}$ & 10.19 & 0.19 & 0.41 & 3.17 & 0.999 \\
\hline OB1 & 8.92 & 0.20 & 0.40 & 5.16 & 0.997 \\
\hline OB2 & 7.59 & 0.21 & 0.40 & 5.66 & 0.996 \\
\hline
\end{tabular}
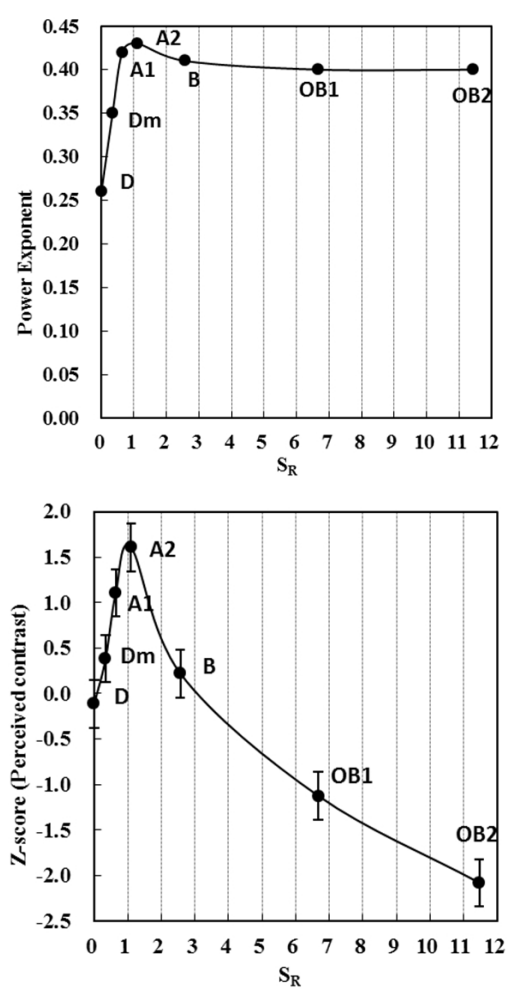

FIG. 5. The change in perceived contrast (top) based on power exponent and (bottom) visual data of previous work [9].
Next, the perceived image contrast is defined by the difference in perceived brightness between white and black stimuli as shown in Table 5. Figure 6 shows the change in brightness difference for seven surround conditions compared with the visual data of our previous work [9]. They are very similar to each other. It is proved that the difference in perceived brightness between white and black stimuli is represented the perceived image contrast for a wide range of luminance from 0 to 12 of $\mathrm{S}_{\mathrm{R}}$.

Finally, the contrast ratio for each surround condition is calculated with Eq. 5, and is also listed in Table 5.

$$
\text { Compensationratio }=\frac{\text { Contrast }_{\text {avarage surround } \mathrm{A} 2}}{\text { Contrast }_{\mathrm{a} \text { surround }}}
$$

The perceived contrast compensation ratios are 1:1.11:1.2

TABLE 5. The brightness difference and contrast compensation ratio

\begin{tabular}{c|c|c|c|c|c|c|c}
\hline \hline & $\mathrm{D}$ & $\mathrm{Dm}$ & $\mathrm{A} 1$ & $\mathrm{~A} 2$ & $\mathrm{~B}$ & $\mathrm{OB} 1$ & $\mathrm{OB} 2$ \\
\hline $\begin{array}{c}\text { Brightness of } \\
\text { white }\end{array}$ & 100.2 & 100.0 & 99.9 & 99.6 & 85.4 & 70.0 & 58.6 \\
\hline $\begin{array}{c}\text { Brightness of } \\
\text { black }\end{array}$ & 19.2 & 12.4 & 7.3 & 2.6 & 2.3 & 2.0 & 1.2 \\
\hline $\begin{array}{c}\text { Brightness } \\
\text { difference }\end{array}$ & 81.0 & 87.6 & 92.6 & 96.9 & 83.1 & 68.0 & 57.5 \\
\hline $\begin{array}{c}\text { Compensation } \\
\text { ratio }\end{array}$ & 1.20 & 1.11 & 1.05 & 1.00 & 1.17 & 1.42 & 1.69 \\
\hline
\end{tabular}
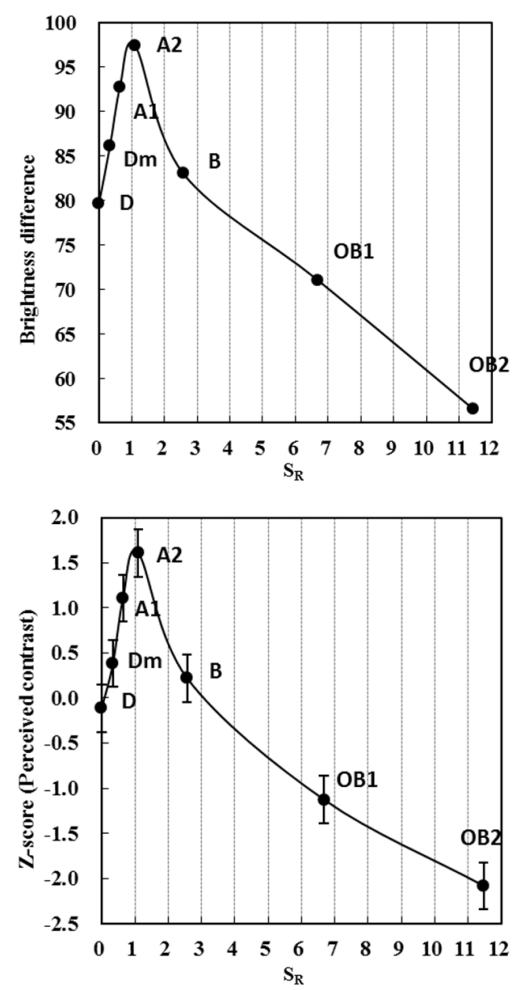

FIG. 6. The change in perceived contrast (top) based on brightness difference and (bottom) visual data of previous work [9]. 
for average, dim and dark surrounds. These are close to CIECAM02 model (1:1.17:1.31). [6] Besides, for average, bright, over-bright 1 and over-bright 2 surrounds the ratios 1:1.17:1.42:1.69 are determined.

\section{CONCLUSION}

The perceived brightness was measured using the magnitude estimation. There were 6 neutral images as test stimulus. Ten observers (seven males and three females) assessed the perceived brightness for each test stimulus under a set of seven surround luminance conditions. The surround conditions were comprised of a wide range of luminance from 0 to $2087 \mathrm{~cd} / \mathrm{m}^{2}$.

To drive the perceived image contrast from the perceived brightness, there were two trials to define the perceived contrast. One was the power exponent $\beta$ of brightness function; the other was the difference in brightness between light and dark areas in a scene. By comparison with the visual data of our previous work, it has been proved that the difference in perceived brightness between white and black stimuli stands for the perceived image contrast for a wide range of luminance from dark to over-bright surround.

In conclusion, the perceived contrast compensation ratios for seven levels of surround luminance could be determined. The perceived contrast compensation ratios were 1:1.11: 1.2 for average, dim and dark surrounds. These were close to CIECAM02 model (1:1.17:1.31). Besides, for average, bright, over-bright 1 and over-bright 2 surrounds the ratios 1:1.17:1.42:1.69 were determined. For intermediate or more extreme surround conditions, the compensation ratio will be obtained from the linear interpolation or extrapolation.

This research shows that current color appearance model, CIECAM02, has to be extended to a wide range of surround luminance. Further research on a color appearance model for bright conditions is required.

\section{REFERENCES}

1. J. C. Stevens and S. S. Stevens, "Brightness function: effects of adaptation," J. Opt. Soc. Am 53, 375-385 (1963).

2. C. J. Bartleson, "Optimum image tone reproduction," Journal of the SMPTE 84, 613-618 (1975).

3. M. D. Fairchild, "Refinement of the RLAB color space," Color Res. Appl. 21, 338-346 (1998).

4. M. D. Fairchild, Color Appearance Models (Addison-Wesley, Messachusette, MA, USA, 1998).

5. M. D. Fairchild, "A revision of CIECAM97s for practical applications," Color Research \& Application 26, 418-427 (2001).

6. N. Moroney, M. D. Fairchild, R. W. Hunt, C. Li, M. R. Luo, and T. Newman, "The CIECAM02 color appearance model," in Proc. IS\&T/SID 10th Color and Imaging Conference (Scottsdale, AZ, USA, 2002), pp. 23-27.

7. C. J. Bartleson and E. J. Breneman, "Brightness perception in complex fields," J. Opt. Soc. Am 57, 953-956 (1967).

8. M. D. Fairchild, "Considering the surround in device independent color imaging," Color Research and Application 20, 352-363 (1995).

9. Y. S. Baek, Y. J. Kim, H. Kim, and S. Park, "Measurement of the optimum surround ratio inducing the highest perceived image contrast," Journal of Electronic Imaging 19, 043013043017 (2010).

10. Y. Park, C. Li, M. R. Luo, Y. Kwak, D. Park, and C. Kim, "Applying CIECAM02 for mobile display viewing conditions," in Proc. IS\&T/SID 15th Color Imaging Conference (Albuquerque, NM, USA, 2007), pp. 169-173.

11. S. Y. Choi, M. R. Luo, and M. R. Pointer, "Colour appearance change of a large sixe display under various illumination conditions," in Proc. SPIE Color Imaging XII: Processing, Hardcopy, and Applications (San Jose, CA, USA, 2007), 649308-01-09.

12. Y. J. Kim and H. Kim, "Spatial luminance contrast sensitivity: effects of surround," J. Opt. Soc. Korea 14, 152-162 (2010).

13. M. R. Luo, A. A. Clarke, P. A. Rhodes, A. Schappo, A. R. Scrivener, and C. J. Tait, "Quantifying colour appearance. Part 1. LUTCHI colour appearance data," Color Res. Appl. 16, 166-180 (1991).

14. J. L. Devore, Probability and Statistics for Engineering and the Sciences (Duxbury Press, Boston, USA, 2011). 